\title{
Risk assessment of a petroleum product pipeline in Nigeria: the realities of managing problems of theft/sabotage
}

\author{
A. Ambituuni ${ }^{1}$, P. Hopkins ${ }^{2}$, J. M. Amezaga ${ }^{1}$, D. Werner $^{1}$ \\ \& J. M. Wood ${ }^{3}$ \\ ${ }^{1}$ School of Civil Engineering and Geoscience, Newcastle University, UK \\ ${ }^{2}$ Penspen Ltd, UK \\ ${ }^{3}$ Pipeline engineering consultant, $U K$
}

\begin{abstract}
Pipelines carrying oil and gas are very safe forms of energy transportation, but they do sometimes fail.

In the Developed World these failures are usually associated with impact damage (e.g. from earth moving equipment), corrosion, or manufacturing faults in the pipeline materials. In the Developing World theft and sabotage is a major, and increasing cause of failure. Countries such as China, Mexico, and Nigeria have major problems with theft of pipeline products, sabotage, and vandalism.

This paper reviews pipeline failures in Nigeria, focusing on pipelines carrying hydrocarbon liquids. The review clearly shows that theft/sabotage is the major cause of failure to pipelines, and the recorded failure rates $(0.35$ per km-year) are well above failure rates reported on other pipeline systems around the world.

Fatalities from pipeline failures range from 0.04 to 0.38 per km-yr, depending on the region in Nigeria. Additionally, on average, the operator of the pipeline system considered in this paper loses about \$US100million/year due to these failures. This value does not consider the costs associated with payment of compensation, fines, environmental clean-ups, litigation, etc. The paper concludes with recommendations to improve pipeline safety systems to reduce these fatalities and costs.
\end{abstract}

Keywords: pipeline risk assessment, petroleum products, theft, sabotage, Nigeria. 


\section{Introduction}

The transportation and distribution of liquid petroleum products in Nigeria is mainly by pipeline and road truck tankers [1]. Pipelines are generally considered the safest form of transporting energy, including petroleum products [2]. Hazards from pipeline operations are due to the possibilities of loss of containment (LOC) [3], with risks of fatality from fire and/or explosions, in addition to environmental damage. Pipeline risk should therefore be assessed in order to develop appropriate mitigation measures.

\subsection{Pipelines in Nigeria}

Fig. 1 shows the pipeline systems used for transporting petroleum products (mainly Premium Motor Spirit (PMS), Automated Gas Oil (AGO) and House Hold Kerosene (HHK)) in Nigeria. The pipeline system is strategically classified into five operational regions. The Nigerian National Petroleum Corporation (NNPC) own and operate the $5001 \mathrm{~km}$ asset through its subsidiary, the Pipeline Petroleum Marketing Company (PPMC). The PPMC pipeline network is made up of multiproduct systems for products supply: the buried pipelines link the refineries with distribution depots. There are 4 refineries in the country: one each in Kaduna and Warri; and two in Port-Harcourt, with a nameplate capacity of 438,750 billion $\mathrm{b} / \mathrm{d}$. The Kaduna refinery is also linked to the Escravos terminal, through Warri, by a crude oil pipeline. The pipelines are divided into nine systems [4].

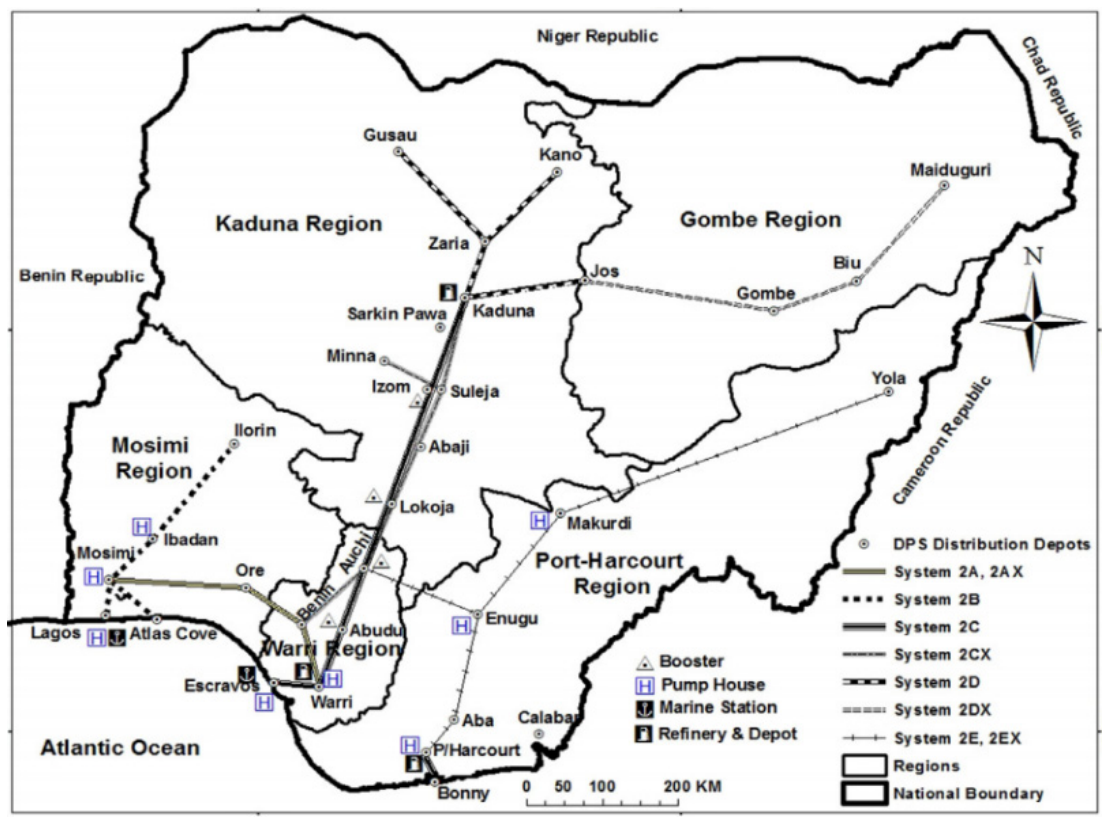

Figure 1: $\quad$ Map of Nigeria showing pipeline network and facilities [4]. 


\subsection{Risk assessment of pipelines}

A full risk assessment of a selected pipeline (such as the system in Fig. 1) is a complex task that may require specialist software (e.g. PHAST, EFFECT, SAFETI) [3] and risk expertise to interpret results correctly. There are a variety of different systems in use for identifying hazards, analysing failure likelihood or probabilities, evaluating failure consequences, and estimating risk values. These systems use qualitative or quantitative assessments to develop a suitable methodology. Palmer-Jones et al. [5] placed the systems into three generic methodologies:

- point-scoring;

- ranking; and,

- $\quad$ quantified $[6,7]$.

This paper considers these three methodologies, and tailors a method utilising analytical techniques that best suit risk assessment of the petroleum product pipelines in Nigeria. The results produced the risk management strategies we recommend in this study.

\subsection{Theft from pipelines}

Pipelines carry many valuable fluids such as crude oil and gasoline: these products have high market values. In recent years, these products have been stolen from pipelines; for example, oil theft costs the Chinese oil industry more than $\$ 124.6 \mathrm{~m}$ (2006 prices), and led to 2,877 arrests [8]. Also, in Mexico, crime groups stole fuel (crude oil, gasoline, diesel, LPG, etc.) estimated at $\$ 250$ million (=3 million barrels) in the first 4 months of 2011. The criminals will make an estimated $\$ 750$ million on stolen fuel this year. The heavily-armed gangs hijack trucks, and also siphon fuel directly from pipelines. The gangs have even built tunnels and pipelines to facilitate the thefts [9]. Associated Press [10] says:

"In 2009, the U.S. Justice Department said U.S. refineries bought millions of dollars worth of oil stolen from Mexican government pipelines and smuggled across the border in illegal operations led by Mexican drug cartels expanding their reach."

The Developed World is also experiencing an increase in theft from pipelines [11]. Figures on liquid pipelines in Western Europe show an increase in theft from pipelines. Various factors contribute to theft/vandalism, e.g.: poverty; lack of basic services; corruption amongst government officials; etc. [12]. Oil theft in Nigeria (the Niger Delta) costs Shell up to $\$ 4.5$ bn a year in lost revenue. Theft from oil pipelines is sophisticated, with a supply and demand chain. The loss of oil from this theft is estimated at 100,000 barrels/day. This theft comes at huge cost. Examples of the human 'cost' of theft, in Nigeria include [8]:

- Dec 2006: > 260 killed in Lagos;

- May 2006: >150 killed in Lagos;

- Dec 2004: >20 killed in Lagos;

- Sept 2004: >60 killed in Lagos;
- June 2003: >105 killed in Abia;

- Jul 2000: >300 killed in Warri;

- Mar 2000: >50 killed in Abia;

- Oct 1998: >1,000 killed in Jesse. 


\section{Methodology of pipeline risk assessment}

The methodology used for analysis of pipeline risk in this study draws relevant techniques from various frameworks. This combines both quantitative and qualitative approaches to obtain results that overcome limitations in the data required for risk assessment of long pipelines, especially in developing countries.

\subsection{Establishing pipeline characteristics}

This involved the collection of pipeline data to establish the general context of the pipeline. We obtained data related to the construction, operation, and maintenance of the pipeline from PPMC. Using this data, it was possible to establishing the characteristics of the pipeline and its operating parameters: including pipeline diameter, wall thickness, steel grade, length, fluid type, line capacity, design flow rate $(\mathrm{min} / \mathrm{max})$, design pressure, cathodic corrosion protection, depth of cover, etc. The details were used for various calculations.

\subsection{Risk analysis using historic data}

Historic incident data was obtained from the pipeline operator (NNPC, PPMC). The historic data used comprised data for 13 years (from 2000-2012) containing information on accidents and failures in the entire $5001 \mathrm{~km}$ pipeline system across the 5 operations and distribution zones. This also includes details of fatalities, quantity and financial value of product loss, failure causal factors, etc.

\subsubsection{Failure frequencies}

Failure frequency is the likelihood that a hazard (pipeline failure) occurs. It is expressed in 1000 kilometre-years. Failure in a pipeline can occur due to a range of potential threats. These threats can be time dependent (e.g. internal/external corrosion and material fatigue), or time independent (e.g. ground movement, third party interference and incorrect operations). Failure of a high pressure pipeline can occur as a leak or rupture. Leaks are defined as fluid loss through a stable defect, while ruptures are fluid loss through an unstable defect which extends during failure, such that the release area is normally equivalent to two open ends [13].

Failure frequency can be computed from historic data. For this study, we adopt and modify the model presented in De Stefani et al. [14] (see eqn (1)). Failure frequency is therefore taken as the sum of reported failures $f$ due to:

- $f_{T P D}$ failure due to third party damage;

- $f_{M F}$ failure from mechanical faults;

- $f_{C O}$ failure from corrosion;

- $f_{N H}$ failure from natural hazard;, and,

- $f_{I N}$ failure from 'interdiction' (sabotage and pilferage).

$$
f=f_{T P D}+f_{M F}+f_{C O}+f_{N H}+f_{I N}
$$




\subsubsection{Consequence analysis}

Consequence analysis involves assessing the effects of accidents in order to determine the severity of pipeline failure. Using historic data, the consequence of releases are assessed at this stage. They include: ignition frequencies; fatality; volume loses; financial loses; and, environmental damage.

\subsubsection{Risk estimation}

Risk estimation is expressed in terms of Societal (SR) and Individual Risk (IR). $\mathrm{SR}$ is a measure of risk to a group of people while IR is defined as a measure of the frequency at which an individual, at a specific distance from the pipeline, may be expected to sustain a specified level of harm from realisation of a specific hazard. IR measures have different values for a given incident or set of incidents. For this study, we assume an individual at a point $x, y$ from the pipeline, and adopted the calculated failure frequencies from eqn (1), and associated ignition frequencies to estimate a value of IR from point $x, y$ with eqn (2). The inspected pipeline ROW in section 2.3 was used as a contextual framework for the calculations.

$$
I R_{(x, y)}=\sum_{j=1}^{n}\left(f . d x \cdot p_{i} \cdot p_{c y}\right)_{j}
$$

$f=$ rupture frequency (per km-yr), $p_{i}=$ ignition probability, $p_{c y}=$ casualty probability, $d x=$ step length $(\mathrm{m})[6]$

\subsection{Condition of right of way: site survey}

To improve the contextual understanding of the pipeline, a site inspection was conducted on a section of the pipeline (system 2B - along the Mosimi to Atlascove section) to obtained site specific data on the condition of right of way. The section of the pipeline inspected was selected due to its importance: $2 \mathrm{~B}$ accounts for $70 \%$ of the product importation. In total, about $13 \mathrm{~km}$ of that section was inspected over a period of four days (from $17^{\text {th }}$ to $20^{\text {th }}$ June, 2014). Details of the inspected coordinates are given in Table 1. The inspected area cuts across towns, villages and countryside.

Table 1: Coordinates of section of pipeline ROW inspected.

\begin{tabular}{|lll|}
\hline Start point coordinate: & $6^{\circ} 35^{\prime} 00.4^{\prime \prime} \mathrm{N}$ & $3^{\circ} 16^{\prime} 15.2^{\prime \prime} \mathrm{E}$ \\
End point coordinate: & $6^{\circ} 27^{\prime} 55.14^{\prime \prime} \mathrm{N}$ & $3^{\circ} 15^{\prime} 14.91^{\prime \prime} \mathrm{E}$ \\
Distance: & $13.26 \mathrm{~km}$ & \\
Initial bearing: & $008^{\circ} 01^{\prime} 00^{\prime \prime}$ & \\
Final bearing: & $008^{\circ} 01^{\prime} 07^{\prime \prime}$ & \\
Midpoint: & $06^{\circ} 31^{\prime} 28^{\prime \prime} \mathrm{N}$ & $003^{\circ} 15^{\prime} 45^{\prime \prime} \mathrm{E}$ \\
\hline
\end{tabular}

\section{Result and discussion}

\subsection{Failure frequencies}

Table 2 shows the regions, the length pipelines, number of reported failures from year 2000 to 2012 and the computed failure frequency per Km year. 
Table 2: $\quad$ Failure frequencies within each NNPC distribution region.

\begin{tabular}{|c|c|c|c|}
\hline Regions & L (km) & $\begin{array}{c}\text { Failure } \\
\text { incidents }\end{array}$ & $\begin{array}{c}\text { Failure frequencies } \\
\text { per km year }\end{array}$ \\
\hline Port-Harcourt (PH) & 1526.6 & 9246 & 0.47 \\
\hline Warri (WR) & 1561.2 & 4659 & 0.23 \\
\hline Mosimi (MS) & 512.6 & 3419 & 0.51 \\
\hline Kaduna (KD) & 1132.8 & 2443 & 0.17 \\
\hline Gombe (GB) & 267.8 & 2642 & 0.76 \\
\hline
\end{tabular}

The 13 year mean value of failure per km-year across the entire NNPC-PPMC pipeline network is 0.351 per km-year. This value is very high compared to failure frequencies from other international data source such as:

- the conservation of clean air and water in Europe (CONCAWE) with a computed failure rate of 0.54E-3 and 0.24E-3 per km-yr from 1971 to 2011 and 2007 to 2011 respectively;

- UKOPA with failure frequency of 0.23E-3 per km-yr from 1962 to 2012; and US with failure rate of 0.135E-3 per km year from 1994 to 2012.

There is therefore a need explore and understand the relationship between high failure rate in Nigeria and causal factors.

Eqn (1) gives the formula for computing failure classification based on causal factors. Failure data from 2000 to 2012 is represented in Table 3. Based on this data, natural hazards $\left(f_{N H}\right)$ is zero. The failure causal classification is limited to two types;

1. Failure due to interdiction $f_{I N}$ - defined as the deliberate or intentional act of destruction on a system such as transport pipeline. This failure classification is believed to be a combination of failure from third party damage $\left(f_{T P D}\right)$ and $f_{I N}$.

2. Failure due to rupture, which is also believed to be a combination of manufacturing faults and corrosion $\left(f_{M F}\right.$ and $\left.f_{C O}\right)$.

As expected, $f_{I N}$ is the largest contributory factor. This failure causal factor has a mean contributory value of $96.49 \%$ of the pipeline failures while failure from rupture (i.e., $f_{M F}$ and $f_{C O}$ ) accounts for $3.51 \%$ (see Table 3 ). Even if the data from interdiction is excluded from the analysis, failure frequency of the pipeline (from 2000 to 2012$)$ remains higher $(0.00757)$ than what is reported internationally. Care needs to be taken in interpreting this result as it does not give in-depth details of causal factors. For instance, the term 'rupture' was given as a failure cause without regards to its technical definition.

$f_{I N}$ has assumed various dimensions within the Nigerian oil and gas industry. Consequently, various terms such as 'oil theft', 'bunkering', 'fuel scooping', 'pipeline sabotage', and 'oil terrorism' have been used to describe the act of illegal tampering to the pipelines. The trend of product pipeline interdiction has evolved in the recent years with possible links to socio-political events. For instance, the likely reason for the increase between 2004 to 2005 (see Fig. 2) the largest in absolute terms - is possibly linked to reported failures to fulfil 
promises made by politicians to the population before the 2003 general elections, especially in the Niger Delta. The increase is mostly influenced by the upsurge in interdiction within the Port-Harcourt region, which forms part of the Niger-Delta [4].

Table 3: $\quad$ Yearly $\%$ failure contributory factors.

\begin{tabular}{ccccc}
\hline Year & $\begin{array}{c}\text { Absolute } \\
\text { F(Interdiction) }\end{array}$ & $\begin{array}{c}\text { F(in)\% } \\
\text { Contribution }\end{array}$ & $\begin{array}{c}\text { Absolute } \\
\text { F(Rupture) }\end{array}$ & $\begin{array}{c}\text { F(Rup) \% } \\
\text { contribution }\end{array}$ \\
\hline $\mathbf{2 0 0 0}$ & 984 & 87.78 & 137 & 12.22 \\
\hline $\mathbf{2 0 0 1}$ & 461 & 94.66 & 26 & 5.34 \\
\hline $\mathbf{2 0 0 2}$ & 516 & 95.20 & 26 & 4.80 \\
\hline $\mathbf{2 0 0 3}$ & 779 & 94.20 & 48 & 5.80 \\
\hline $\mathbf{2 0 0 4}$ & 895 & 92.17 & 76 & 7.83 \\
\hline $\mathbf{2 0 0 5}$ & 2237 & 99.07 & 21 & 0.93 \\
\hline $\mathbf{2 0 0 6}$ & 3674 & 99.76 & 9 & 0.24 \\
\hline $\mathbf{2 0 0 7}$ & 3224 & 99.38 & 20 & 0.62 \\
\hline $\mathbf{2 0 0 8}$ & 2285 & 98.58 & 33 & 1.42 \\
\hline $\mathbf{2 0 0 9}$ & 1453 & 98.18 & 27 & 1.82 \\
\hline $\mathbf{2 0 1 0}$ & 836 & 97.21 & 24 & 2.79 \\
\hline $\mathbf{2 0 1 1}$ & 2768 & 99.32 & 19 & 0.68 \\
\hline $\mathbf{2 0 1 2}$ & 2230 & 98.85 & 26 & 1.15 \\
\hline
\end{tabular}

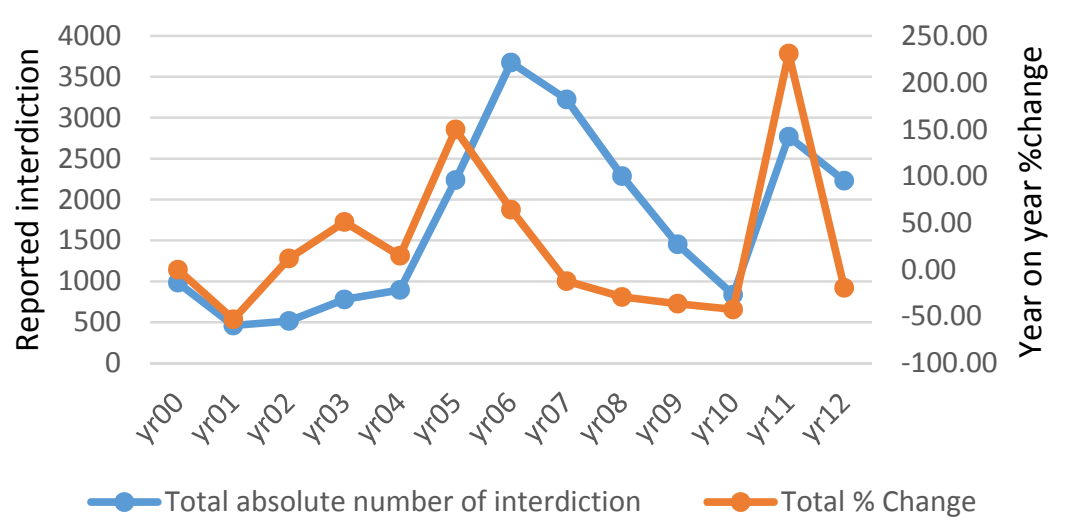

Figure 2: Total national absolute number of interdiction and $\%$ change.

The drop in national interdiction figure within 2006 to 2010 may be attributed to the amnesty granted to ex-militants by the Nigerian Government. The programme appears to have substantially reduced interdiction until 2010. From 2010 to 2011 , interdiction increased over $200 \%$, making it the highest national percentage increase on record. This was the period of general elections. It is 
therefore noted that interdiction and failure frequencies on pipelines in Nigeria may be influenced by socio-political events. With this knowledge, security can be enhanced along the pipeline as periods of general elections approach.

\subsection{Failure frequency and age of pipeline}

The pipeline systems were constructed in two periods: 1978/80 and 1995. From Table 4 it can be seen that there is a significant difference between failures from interdiction across the two construction periods. The newer lines have a higher hit rate. This reveals that interdictors attack lines irrespective of the age of the pipeline. Failure due to rupture increased with pipeline age; unfortunately, the available data did not permit further analysis to ascertain the precise relationships (i.e., whether the failure is related to time dependent threats (e.g. internal/external corrosion and material fatigue) or time independent (e.g., ground movement and incorrect operations).

Table 4: $\quad$ Pipeline age and mean failure frequency. Note that $f_{I N}$ is failure due to interdiction and $f_{R u p}$ is failure due to rupture.

\begin{tabular}{|c|c|c|c|c|c|}
\hline Variable & N (yrs) & Mean & StDev & Minimum & Maximum \\
\hline$F_{I N}(1995)$ & 13 & 0.493 & 0.428 & 0.057 & 1.180 \\
\hline$F_{I N}(1978 / 80)$ & 13 & 0.765 & 1.065 & 0.000 & 3.208 \\
\hline$f_{\text {Rup }}(1995)$ & 13 & 0.02011 & 0.01230 & 0.00390 & 0.03902 \\
\hline$f_{\text {Rup }}(1978 / 80)$ & 13 & 0.00203 & 0.00365 & 0.00000 & 0.01132 \\
\hline
\end{tabular}

\subsection{Consequence analysis}

The consequences of pipeline failure are examined in this section.

\subsubsection{Ignition causes and frequencies $\left(p_{i}\right)$}

Failure records from 2007 had causes of ignition. Prior to 2007, only the numbers of ignitions recorded per year were reported. Of the 106 ignitions recorded from 2007 to 2012, about 75\% were as a result of (Fig. 3):

- deliberate arson after scooping fuel;

- unintentional fire as a result of scooping; or,

- bomb attack.

Most of the sources of fire from mechanical faults are not clearly reported; however, one incident was attributed to sudden rupture. Third party damage is not a major causal factor, but sparks from electric overhead cables, bush burning for hunting purposes, and construction activities were mostly the source of fire from third part damage. From Table 5 it can be seen that Port-Harcourt region (PH), Warri (WR), Mosimi (MS) and Kaduna regions all have ignition per failure incidents within the same range (i.e., about 1 in 50), while Gombe (GB) region recorded the lowest ignition frequency of approximately 1 in 100 reported failures. There are questions as to the reason why ignition rate is high in PH, WR and MS regions. Perhaps this could be associated to the type of technology used in illegal hot tapping, or the flash point of the product involved. However, 
emergency response capability can be enhanced to reduce such incidents with this information. Leak detection and incident response technologies should focus on the high risk regions.

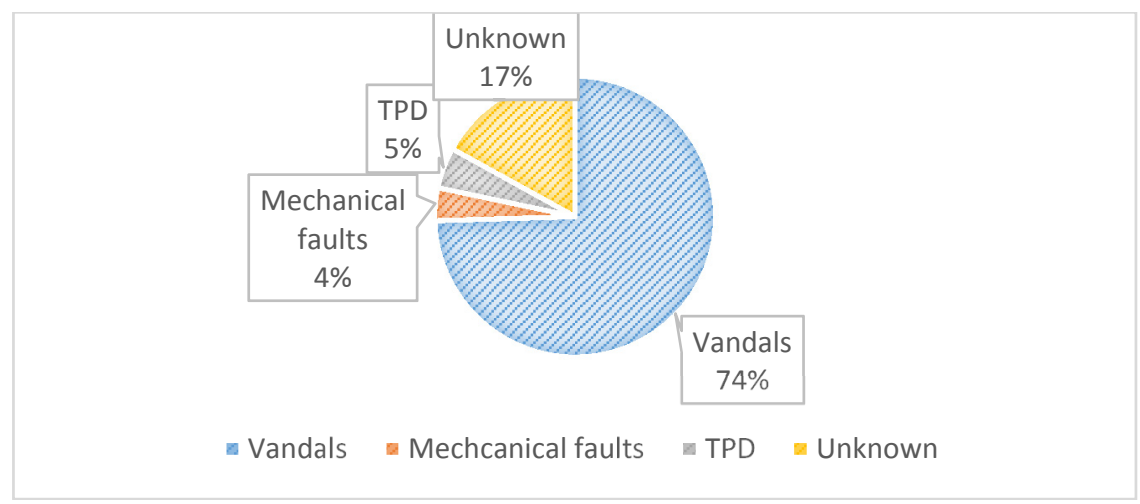

Figure 3: Ignition causal factors.

Table 5: $\quad$ Ignition frequencies within NNPC-PPMC distribution regions.

\begin{tabular}{cccc}
\hline Regions & $\begin{array}{c}\text { Pipeline failure } \\
\text { (2000 to 2012) }\end{array}$ & $\begin{array}{c}\text { Fire incidents } \\
\text { (2000 to 2012) }\end{array}$ & $\begin{array}{c}\text { Ignition } \\
\text { frequency }\end{array}$ \\
\hline PH & 9246 & 206 & $2.23 \mathrm{E}-02$ \\
\hline WR & 4659 & 122 & $2.62 \mathrm{E}-02$ \\
\hline MS & 3419 & 76 & $2.22 \mathrm{E}-02$ \\
\hline KD & 2443 & 50 & $2.05 \mathrm{E}-02$ \\
\hline GB & 2642 & 27 & $1.02 \mathrm{E}-02$ \\
\hline
\end{tabular}

\subsubsection{Fatality}

The fatality of a pipeline failure within each distribution region (as represented in Table 6) can be determined. No fatality has been recorded from pipeline failures in GB and KD regions. On average, the pipeline systems in PH, WR and MS regions recorded fatality of $0.044,0.071$ and 0.38 per km-yr. These fatality rates could be a direct function of the high ignition frequencies within these regions. However, surprisingly, KD region recorded no fatality even though the ignition frequency in that region is similar to ignition frequencies in PH, WR and MS. This suggests that other influencing factors (as discovered during the pipeline right of way inspection) may include the proximity of buildings to the pipeline, incident response time, ease of access to incident sites, etc.

\subsubsection{Product losses and financial values}

The scale of problem of product losses can be seen in financial terms in Fig. 4. From this figure, the spike in 2005-2006 and 2011-2012 may be related to the political issues discussed in section 2.1. On average, the operator loses about 100 million USD per year. This value does not even considers cost associated with payment of compensation, fines, environmental clean ups, litigation, etc. 
58 Safety and Security Engineering VI

Table 6: $\quad$ Fatalities from 1998 to 2012. Updating from Anifowose et al. [4].

\begin{tabular}{cc}
\hline Regions & Fatality report (1998 to 2012) \\
\hline PH & 1004 \\
\hline WR & 1665 \\
\hline MS & 2889 \\
\hline GD & 0 \\
\hline
\end{tabular}

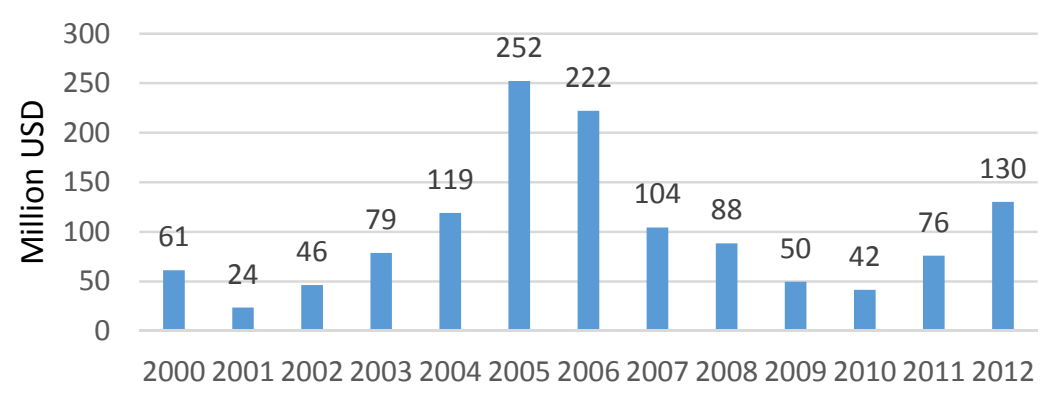

Figure 4: Dollar value of product loss.

\subsection{Individual risk based on historic data}

Fig. 5 illustrates the calculated IR associated with the section of the pipeline inspected. The figure also illustrates the IR limits established by BSI PD8010-3 [13]. At about $40 \mathrm{~m}$ from the pipeline, the IR value is not within the BSI PD tolerable limits. Above 40m the IR value is tolerable if the risk is ALARP. The

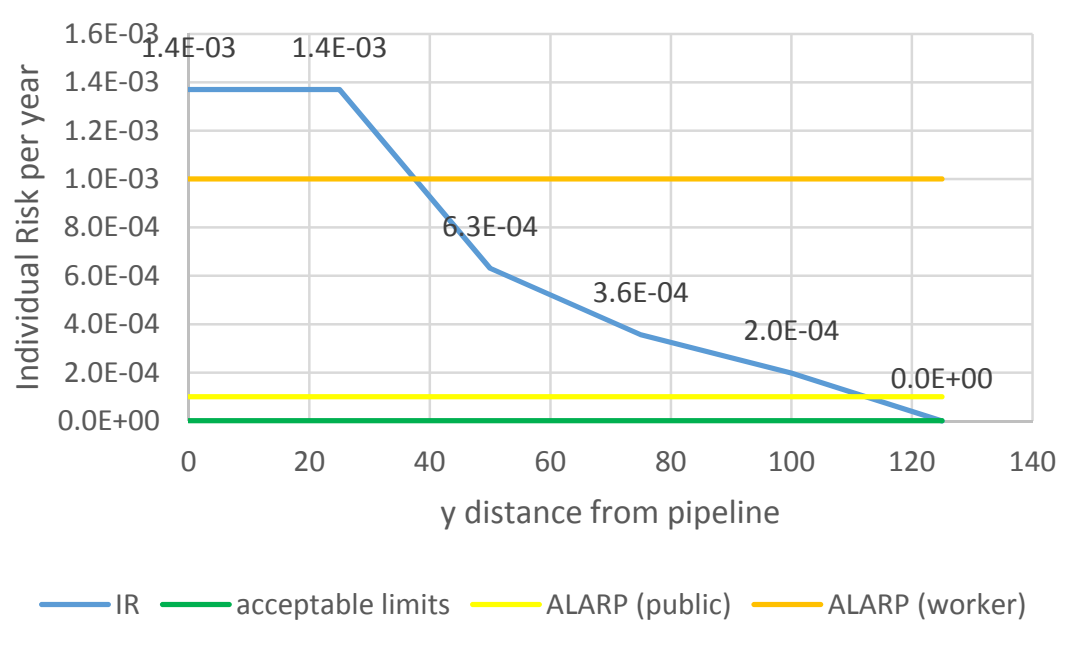

Figure 5: Pipeline IR values. 
ROW inspection conducted reveals that in many cases buildings and other public infrastructures are located less that a meter from the pipeline. This may be the reason for the high fatality rates.

\section{Conclusion}

The risk associated with the Nigerian petroleum product pipelines was assessed using historic data and site data. The failure frequency of the pipelines was found to be extremely high ( 0.351 per km-yr) when compared to failure frequencies of international pipelines (e.g., the UK and USA). This is mainly due to pipeline interdiction. Consequently, the ignition frequencies, fatality, and product losses from the Nigerian pipelines are found to be high. This ultimately made the values of Individual Risk for these pipelines to fall outside tolerable limits.

Although we recognise that the poor safety performance of the pipelines are influenced by wider socio-political issues in Nigeria, the information provided via this assessment, and some concepts of engineering and pipeline risk and integrity management, can help in managing and optimising the performance of the pipeline. Hence, in Section 5 we make recommendations to improve the pipeline's safety and environmental management system.

\section{Risk management recommendations}

1. The pattern of interdiction on these pipelines reveals how the pipeline industry is affected by socio-political issues. Therefore, these issues should be an integral part of the pipeline risk management. To better understand the dynamics of these issues, a detailed Environmental and Social Impact Assessment (ESIA) should be conducted across the entire network. Aggrieved communities should be identified, a royalty payment system should be designed as compensation to land owners, and community incident reporting/response system should be enhanced using the 'one-call' system.

2. Inline inspections and air surveillance systems should be designed and implemented. Inspection can be carried out internally by X-ray or Gamma ray crawlers or intelligent pigs. These enable the detection of internal and external corrosion, drill holes, and cracks within the wall of the pipeline. The intervals of inspection and frequencies of surveillance can be extrapolated from the assessed pattern of failure frequencies in this study. Surveillance should be vigorous, especially in political election years.

3. Optical intrusion electronic detection systems can be used to monitor activities of interdictors. The system includes a fibre optic, usually installed 12 to 24 inch above the pipeline. Should the cable become damaged, the monitoring device issues an alarm to the pipeline logic controller and/or the supervisory control and data system. Response can then be initiated.

4. Public education needs to be enhanced. Individuals (especially within intolerable risk zone) should be educated about the hazardous nature of petroleum products, pipeline dangers, and appropriate emergency responses. 
5. The pipelines' rights of way need to be properly maintained. Encroachment of buildings should be stopped, with strict regulations and appropriated land compensations.

\section{Acknowledgement}

This paper is part of a three year $\mathrm{PhD}$ research at Newcastle University funded by the Petroleum Technology Development Fund (PTDF), Nigeria.

\section{References}

[1] A. Ambituuni, J. Amezaga, E. Emeseh, Analysis of safety and environmental regulations for downstream petroleum industry operations in Nigeria: Problems and prospects. Environmental Development 9 (2014) 43-60.

[2] P. Hopkins, Why failure happen and how to prevent future failures, International Congress on Logistics, Transportation and Distribution of Hydrocarbon., J. Pipeline Eng., Guadalajara, Mexico, 2012, pp. 77-91.

[3] M. Dziubiński, M. Frątczak, A.S. Markowski, Aspects of risk analysis associated with major failures of fuel pipelines. J. Loss Prev. Process Ind. 19 (2006) 399-408.

[4] B. Anifowose, D.M. Lawler, D. van der Horst, L. Chapman, Attacks on oil transport pipelines in Nigeria: A quantitative exploration and possible explanation of observed patterns. Applied Geography 32 (2012) 636-651.

[5] R. Palmer-Jones, S. Turner, P. Hopkins, A new approach to risk-based pipeline-integrity management. The J. Pipeline Eng. 8 (2009) 229-239.

[6] Y.D. Jo, J.A. Bum, A method of quantitative risk assessment for transmission pipeline carrying natural gas. Journal of hazardous materials 123 (2005) 1-12.

[7] W.K. Muhlbauer, Pipeline Risk Management Manual: Ideas, Techniques, and Resources, Elsevier, 2004.

[8] BBC, BBC News 2006.

[9] A. Harrup, D. Luhnow, Mexican Crime Gangs Expand Fuel Thefts, The Wall Street Journal, The Wall Street Journal, 2011.

[10] E. E. Castillo, Associated Press on MSNBC 2010.

[11] Anon., 2013 Performance of European cross-country oil pipelines. Statistical summary of reported spillages in 2011 and since 1971, CONCAWE.

[12] H. C. Imig, "Mitigating Risks". World Pipelines 10 (2010) 109.

[13] PD8010-3, BSI Standards Pipeline systems -Part 3: Steel pipelines on land - Guide to the application of pipeline risk assessment to proposed developments in the vicinity of major accident hazard pipelines containing flammables, BSI Standards Publication 2013.

[14] V. De Stefani, W. Zoe, A. Micheal, A Model to Evaluate Pipeline Failure Frequencies Based on Design and Operating Conditions, 2009 Spring Meeting \& 5th Global Congress on Process Safety, Center for Chemical Process Safety (CCPS) 24th International Conference, 2009. 